\title{
Dataset Citra Papan Sirkuit Tercetak dengan Komponen yang Terbakar
}

\author{
Iwan Awaludin, Trisna Gelar*, Muhammad Rizqi Sholahuddin, Gina Melinia, Irvan Kadhafi, Rezky \\ Wahyuda Sitepu
}

Teknik Komputer dan Informatika, D3 Teknik Informatika, Politeknik Negeri Bandung, Bandung, Indonesia Email: ${ }^{1}$ iwan.awaludin@ polban.ac.id, ${ }^{2,}{ }^{*}$ trisna.gelar@ polban.ac.id, ${ }^{3}$ muhammad.rizqi@ jtk.polban.ac.id, ${ }^{4}$ gina.melinia.tif18@polban.ac.id, ${ }^{5}$ irvan.kadhafi.tif18@polban.ac.id, ${ }^{6}$ rezky.wahyuda.tif18@polban.ac.id Email Penulis Korespondensi: trisna.gelar@polban.ac.id

Submitted: 14/12/2021; Accepted: 25/12/2021; Published: 31/12/2021

\begin{abstract}
Abstrak-Aplikasi kecerdasan buatan terutama dalam bidang inspeksi optis otomatis papan sirkuit tercetak atau Printed Circuit Board (PCB) semakin banyak dikerjakan oleh peneliti. Sayangnya selama ini data yang dipakai untuk melatih dan menguji model kecerdasan buatan merupakan data sintetis. Papan sirkuit tercetak dalam kondisi bagus diambil citranya dan kemudian diubah dengan perangkat lunak untuk mendapat kesan kerusakan. Selain itu jenis kerusakan terbatas pada pra-operasional yaitu ketika PCB belum beroperasi. Setelah PCB beroperasi kerusakan bisa terjadi misalnya komponen yang terbakar. Sampai saat ini belum ada kumpulan data citra PCB dengan komponen yang terbakar. Karena itu penelitian ini mengeksplorasi teknik pengambilan data yang bisa menghasilkan kumpulan data yang diperlukan. Teknik pengambilan data ini termasuk di dalamnya setup perangkat keras dan sumber-sumber data PCB. Berdasarkan hasil eksplorasi diperoleh simpulan bahwa: mikroskop digital trinokuler dengan resolusi tinggi bisa menghasilkan citra PCB yang tajam. Hambatan yang muncul adalah kesulitan untuk mendapatkan PCB dengan komponen terbakar. Solusi didapatkan dengan merujuk pada video reparasi PCB dari kanal Youtube. Sejumlah data berhasil dikumpulkan dan dicoba dengan EfficientDet dengan mAP $90 \%$.
\end{abstract}

Kata Kunci: Dataset; Deep Learning; EfficientDet; Komponen Terbakar; Printed Circuit Board.

\begin{abstract}
The application of artificial intelligence, especially in automatic optical inspection of printed circuit boards or PCBs, is increasingly being carried out by researchers. Unfortunately, the data used to train and test artificial intelligence models is synthetic data. Printed circuit boards in good condition are imaged and then changed by software to give the impression of defects. In addition, the type of damage is limited to pre-operation, namely when the PCB is not yet operational. After the PCB is operational, damage can occur, for example, burned components. Until now, there is no data set of PCB images with burned components. This study therefore explores data retrieval techniques that can produce the required data set. This data collection technique includes hardware setup and PCB data sources. Based on the exploration results, it is concluded that a trinocular digital microscope with high resolution can produce sharp PCB images. The obstacle that arises is the difficulty of getting PCBs with burned components. The solution was obtained by referring to the PCB repair video from the Youtube channel. Several data were collected and tested with EfficientDet with $90 \%$ mAP.
\end{abstract}

Keywords: Dataset; Deep Learning; EfficientDet; Burnout Component; Printed Circuit Board

\section{PENDAHULUAN}

Dalam era digital, teknologi elektronik digunakan hampir dalam setiap bidang kehidupan. Papan sirkuit tercetak (Printed Circuit Board, PCB) adalah komponen penting untuk teknologi elektronik dan industri saat ini. Hampir setiap perangkat elektronik memiliki salah satu modul mandiri dari komponen elektronik kompleks yang saling berhubungan, yang meliputi resistor, kapasitor, transistor, diode, dan sekering. Kerusakan PCB merupakan suatu hal yang tidak bisa dihindari baik dalam proses produksinya maupun setelah PCB tersebut digunakan. Pada banyak kesempatan, kerusakan PCB dapat diperbaiki sehingga sistem yang menggunakannya dapat berfungsi kembali. Kerusakan ini diidentifikasi melalui inspeksi langsung oleh teknisi berpengalaman ataupun dengan menggunakan bantuan Automatic Optical Inspection (AOI). Karena PCB menjadi semakin rumit, tugas deteksi dan klasifikasi cacat juga lebih sulit dari sebelumnya. Beberapa AOI telah menggunakan metode identifikasi dan klasifikasi berbasis kecerdasan buatan. Misalnya [1]-[3] menggunakan berbagai macam kecerdasan buatan seperti Convolutional Neural Network dan Mobile-Net untuk mendeteksi berbagai macam kerusakan pada PCB. Kerusakan pada PCB ada banyak jenisnya. Misalnya jalur yang terpotong, lubang yang hilang, komponen yang hilang, dan lainnya. Setiap jenis kerusakan memerlukan kumpulan data khusus yang digunakan untuk melatih model-model kecerdasan buatan. Sampai saat ini kumpulan data PCB hanya tersedia untuk kerusakan jalur terpotong, tembaga berlebih, lubang yang hilang, dan komponen yang hilang. Sementara itu dalam dunia nyata banyak kasus terkait dengan komponen yang terbakar. Pada PCB dengan komponen yang besar maka komponen terbakar ini dapat terlihat dengan jelas. Sedangkan pada PCB dengan komponen yang kecil, komponen terbakar ini sulit terlihat dengan mata telanjang. Karena itu diperlukan bantuan perangkat seperti mikroskop digital untuk menemukan komponen yang terbakar ini. Pekerjaan mencari komponen kecil yang terbakar cukup melelahkan dan memerlukan ketelitian tinggi. Dengan tersedianya data dari kamera mikroskop digital maka dimungkinkan untuk menerapkan kecerdasan buatan dengan tujuan menemukan komponen terbakar ini. Sayangnya belum ada kumpulan data PCB dengan komponen terbakar yang bisa digunakan untuk melatih kecerdasan buatan. Karena itu penelitian ini bertujuan untuk mengumpulkan data PCB dengan komponen terbakar yang bisa digunakan untuk melatih kecerdasan buatan. Proses pengumpulan akan termasuk di dalamnya sumber-sumber primer dan sekunder, setup perangkat akuisisi data, dan juga pra-pemrosesan sebelum bisa digunakan oleh model-model kecerdasan buatan. 


\section{METODOLOGI PENELITIAN}

Penelitian dilakukan dengan langkah studi literatur, eksperimen dengan beberapa macam kamera dan mikroskop digital, pengambilan data citra dari sumber primer, anotasi citra, konversi anotasi ke csv, konversi csv ke format TFRecord, Eksperimen dengan Google Colab.

\subsection{Studi Literatur}

Sebelum kumpulan data PCB dengan komponen terbakar diperoleh, perlu diperhatikan bagaimana peneliti lain mendapatkan kumpulan data PCB-nya. Ada beberapa peneliti yang mendapatkan datanya dari hasil eksperimen sendiri dan lebih banyak yang memakai kumpulan data yang disediakan secara publik oleh peneliti lain. Penggunaan kumpulan data yang disediakan secara publik oleh peneliti memungkinkan peneliti lain membandingkan performa model yang berbeda dengan data yang sama. Beberapa contoh kumpulan data citra PCB diberikan sebagai berikut. DeepPCB [4] mengumpulkan data PCB dari template desain dipindai menggunakan scanner CCD sehingga diperoleh data digitalnya. Dari template ini ditambahkan kerusakan yang diinginkan seperti jalur terpotong, jalur terhubung singkat, tembaga berlebih, lubang hilang, dan lainnya. Anotasi diberikan terhadap tambahan kerusakan tersebut dan kemudian digunakan untuk melatih model kecerdasan buatan.

Data lain misalnya dari http://robotics.pkusz.edu.cn/resources/dataset/ [5] diperoleh data PCBA-defect dengan enam jenis kerusakan seperti lubang yang hilang, gigitan tikus, jalur terhubung, dan lainnya. Ada 1386 citra sintetis yang artinya kerusakan yang ada dalam PCB dibuat manual dengan mengubah citra asli. Citra tersebut dikumpulkan sejak tahun 2018. Citra PCB diambil dengan menggunakan mikroskop digital khusus untuk PCB. Orientasi dari PCB saat pengambilan citra dibuat acak sehingga diperoleh citra yang berbeda dari sebuah PCB. Setelah itu citra diubah memakai software Adobe Photoshop untuk menambahkan kerusakan-kerusakan yang diinginkan. Hasil ubahan tersebut kemudian dianotasi untuk menentukan posisi kerusakan dengan jenis kerusakannya.

Kumpulan data citra ini digunakan dalam[1], [6]dengan model kecerdasan buatan berbeda. Hasilnya adalah komparasi antara model baru yang diajukan (SSIM) dengan model yang sudah ada seperti You Only Look Once (Yolo) Versi [7], Faster RCNN[8], dan TDD-Net[9]. PCB-DSLR [10] menyediakan kumpulan citra PCB dengan tujuan identifikasi Integrated Circuit (IC) yang berdimensi besar. Citra dengan jumlah ribuan diambil dari PCB penuh menggunakan kamera Digital Single Lens Reflex (DSLR). Orientasi dari PCB diubah sehingga didapat tambahan data yang cukup signifikan. Anotasi diberikan kepada Integrated Circuit (IC) saja, tidak kepada komponen lain.

Tetapi kumpulan data seperti itu tidak membawa manfaat yang banyak karena hanya bisa digunakan untuk mengidentifikasi IC dimensi besar dan lokasinya saja. Sementara itu keperluan lain adalah untuk mengidentifikasi jenis komponen seperti resistor, kapasitor, induktor, dan lainnya. Karena itu peneliti seperti [11] membuat kumpulan data PCB-Metal sendiri dengan kamera DSLR. Jumlah citra yang berhasil dikumpulkan adalah 984 buah dari 123 PCB berbeda. Artinya orientasi pengambilan gambar dibuat berbeda sehingga diperoleh citra yang berbeda.

Kumpulan data paling baru dipublikasikan oleh [12] yang berisi data anotasi komponen seperti PCB-Metal. Data dikumpulkan dengan memakai kamera DSLR dan mikroskop digital khusus PCB. Jumlah citra yang berhasil diperoleh adalah 9912 buah dari 31 PCB. Tidak seperti kumpulan data lain, FICS PCB membedakan iluminasi pencahayaan, orientasi, skala, dan sensor sehingga diperoleh citra yang sangat banyak.

Sebagai ringkasan, kumpulan data yang dipublikasikan oleh peneliti sebelumnya diambil menggunakan mikroskop digital khusus PCB atau kamera DSLR. Tujuan dari penggunaan citra adalah untuk mendeteksi kerusakan pada jalur dan identifikasi komponen. Jumlah citra jauh lebih banyak daripada jumlah PCB dengan pembeda orientasi, pencahayaan, skala, dan jenis sensor. Ringkasan ini disarikan dalam Tabel 1 berikut. Dari data tersebut bisa disimpulkan bahwa belum ada kumpulan data yang khusus digunakan untuk mengidentifikasi kerusakan komponen terbakar. Citra PCB dengan kerusakan bisa dikatakan tidak ada dari PCB sebenarnya. Semua data PCB dengan kerusakan ditambahkan pada citra dengan kondisi baik secara sintetis.

Tabel 1. Klasifikasi Dataset

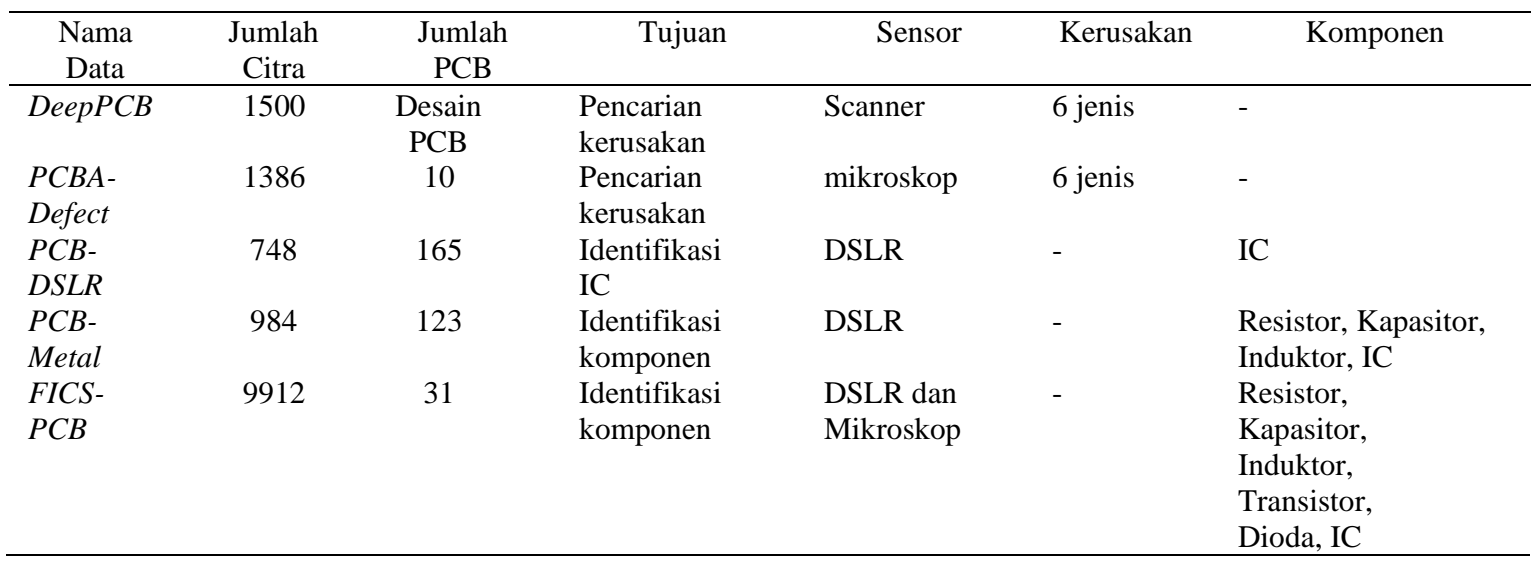




\subsection{Pengumpulan Data}

Kerusakan PCB ada banyak jenis dan penyebabnya. Khusus untuk kerusakan komponen terbakar banyak terjadi pada PCB yang telah digunakan dalam satu sistem. Secara umum komponen terbakar banyak terjadi di bagian daya dari PCB. Sangat jarang terjadi komponen terbakar pada jalur komunikasi atau logika dari PCB. Umumnya bagian daya dari PCB terdiri atas komponen resistor, diode, kapasitor, induktor, dan mosfet. Lokasi dari bagian daya ini biasanya ada di dekat sumber daya. Bagian daya ini berfungsi untuk mengubah level tegangan, membagi beban, dan distribusi daya ke bagian lain dari PCB. Pada perangkat digital terkini, komponen dari bagian daya ini memiliki bentuk fisik yang kecil. Pemeriksaan langsung oleh mata mungkin tidak dapat menemukan kerusakan komponen terbakar. Karena itu diperlukan bantuan kamera digital yang dapat memperbesar tampilan dari komponen.

Ada banyak pilihan kamera digital. Pada bagian studi literatur secara umum kamera yang digunakan adalah kamera khusus mikroskop digital dan DSLR. Dalam penelitian ini akan dieksplorasi beberapa alternatif kamera yang mungkin bisa digunakan dengan harga yang cukup terjangkau. Alternatif yang menjadi pilihan adalah webcam, kamera mirrorless, dan mikroskop digital dengan spesifikasi yang berbeda. Webcam yang dipakai dalam eksplorasi ini adalah Logitech C920 dengan spesifikasi Full HD 1080p. Webcam bisa dikenali langsung oleh berbagai macam sistem operasi. Pengambilan gambar bisa dilakukan langsung dari komputer dengan aplikasi bawaan sistem operasi. Kamera ini dapat diatur zoom dan fokusnya melalui software bawaan Logitech yaitu dengan bantuan slider. Citra yang diambil oleh kamera webcam dapat fokus di tengah tetapi kabur di bagian pinggir seperti diperlihatkan pada Gambar 1 .

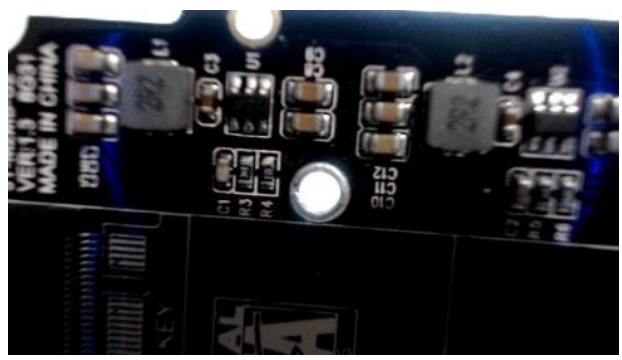

Gambar 1. Contoh Citra PCB Hasil Pengambilan Kamera Webcam Logitech C920

Kamera DSLR dan kamera mirrorless memiliki fungsi yang sama dengan teknologi yang berbeda. Kebanyakan kamera DSLR dan mirrorless tidak memungkinkan pengambilan gambar langsung dari komputer. Pengaturan fokus otomatis tidak memungkinkan mendapat citra komponen yang bagus. Biasanya acuan fokus adalah komponen yang tertinggi di PCB seperti kapasitor besar, jack audio, dan jack kartu jaringan. Akibatnya komponen yang menjadi perhatian seperti resistor dan kapasitor tidak bisa dilihat dengan jelas.

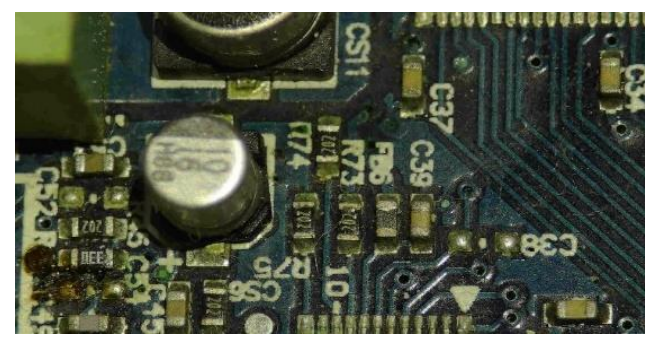

Gambar 2. Contoh Citra PCB Hasil Pengambilan Kamera Mirrorless Olympus E-PL1

Kamera perangkat bergerak seperti smartphone memiliki kualitas citra yang cukup bagus. Tetapi masalah yang sama dengan kamera DSLR juga ada dalam kamera perangkat bergerak. Pengaturan fokus tidak bisa dilakukan oleh software di komputer dan auto-fokusnya menangkap komponen tertinggi di PCB. Akibatnya kamera perangkat bergerak tidak cocok digunakan untuk identifikasi komponen terbakar. Selain itu tanpa bantuan lensa khusus makro maka hasil pengambilan citra PCB dari jarak dekat tidak memberikan hasil yang baik.

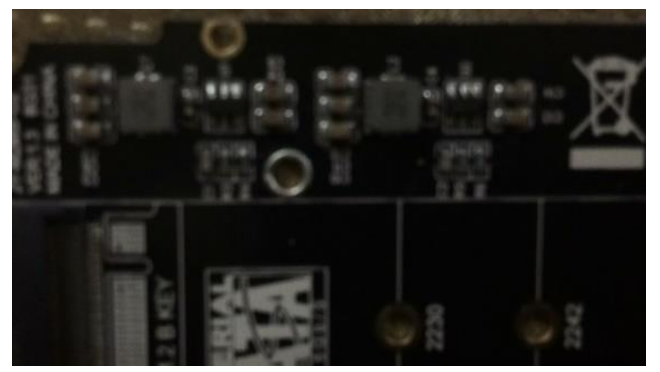

Gambar 3. Contoh Citra PCB Hasil Pengambilan Kamera HP 
Mikroskop digital tersedia dalam rentang harga yang bervariasi. Antar muka tersedia dalam koneksi USB, HDMI, VGA, dan bahkan memiliki layar sendiri. Karena data citra akan dikumpulkan maka dipilih mikroskop dengan antar muka USB. Semua kamera mikroskop dengan USB dapat dikenali oleh sistem operasi Linux dan Windows. Mikroskop dengan harga murah tidak dapat memberikan hasil citra yang cukup tajam. Luas area PCB yang dapat diamati juga tidak besar. Disarankan agar memakai mikroskop dengan resolusi minimal 14mp untuk memperoleh citra yang cukup jelas.

Kamera mikroskop dengan antar muka USB tersedia dengan lensa fixed dan flexible. Untuk lensa yang fixed jarak pengamatan dan fokus lensa tidak dapat diatur dengan baik. Sedangkan lensa flexible dapat dipilih dengan pembesaran yang berbeda dengan jenis mounting lensa $C$-Mount. Pembesaran yang tersedia di pasaran Indonesia adalah 100x, 180x, 200x, dan 300x. Semakin besar pembesaran maka semakin dekat posisi lensa terhadap PCB. Idealnya pembesaran dilakukan sebesar 20x untuk memperoleh bidang pengamatan yang cukup besar. Tetapi lensa yang tersedia paling kecil 100x dengan jarak maksimum lensa terhadap PCB adalah $15 \mathrm{~cm}$. Luas bidang PCB yang bisa diamati adalah $400 \mathrm{~mm}^{2}$.

Mikroskop yang paling tepat untuk pengambilan citra PCB adalah mikroskop trinokuler di mana fokus kamera dapat diatur dengan pembesaran mulai 8 - $300 \mathrm{x}$. Dengan pembesaran seperti ini jarak antara lensa dengan PCB tidak terlalu dekat dengan detail yang cukup baik. Gambar 4a, 4b, dan 4c menunjukkan hasil pengambilan citra PCB dengan mikroskop yang sama tetapi menggunakan kamera yang berbeda. Gambar 4a menggunakan kamera resolusi $14 \mathrm{mp}$ sedangkan Gambar 4b dan 4c resolusi 41mp. Dengan pencahayaan yang sama, citra yang dihasilkan oleh kamera dengan resolusi lebih tinggi terlihat lebih jelas. Bahkan setelah citra diperbesar, Gambar 4c masih memberikan tingkat kecerahan yang sama dengan Gambar 4b.

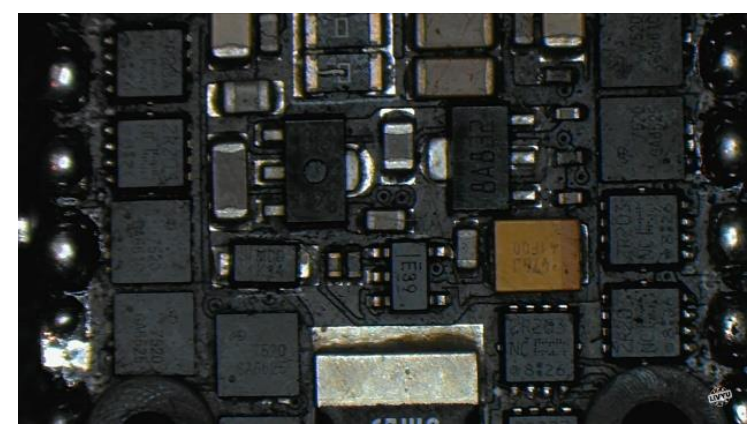

a

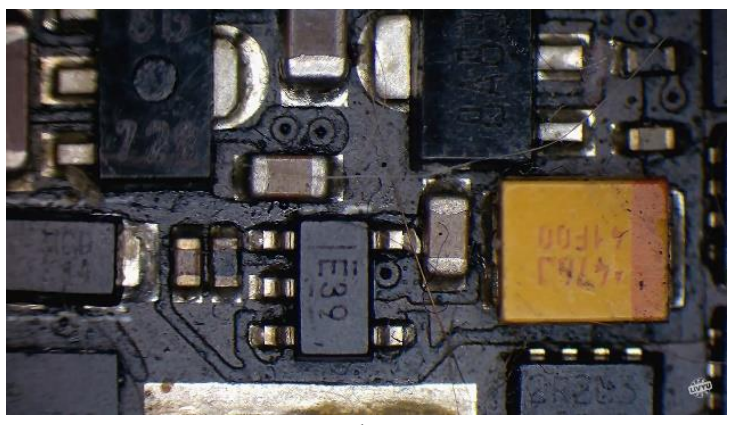

b

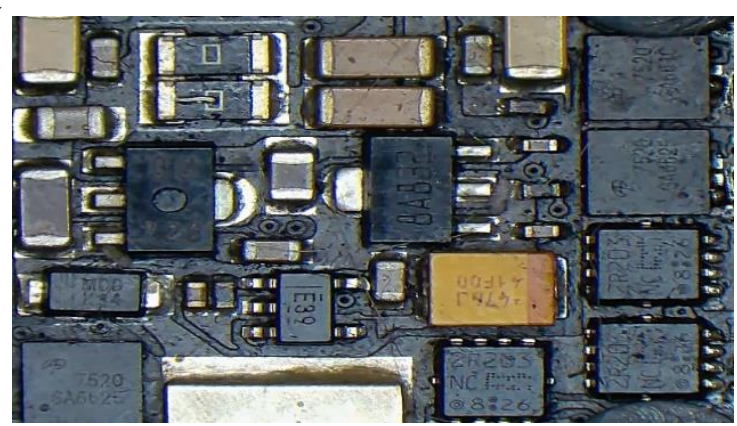

C

Gambar 4. a. Pengambilan Citra PCB dengan Mikroskop Trinokuler 14mp; b. Pengambilan Citra PCB dengan Mikroskop Trinokuler 41mp Zoom In. c. Pengambilan Citra PCB dengan Mikroskop Trinokuler $41 \mathrm{mp}$.

Setelah setup peralatan siap, maka selanjutnya adalah pengambilan data. Data bisa dikumpulkan sebagai data primer, sekunder, atau tertier. Jika pengambilan data menggunakan PCB dan peralatan sendiri maka bisa dimasukkan dalam kategori data primer. Untuk keperluan ini maka harus dikumpulkan PCB dengan komponen yang terbakar.

PCB bekas tersedia di marketplace dan juga toko luring. Tetapi untuk mendapatkan PCB dengan kerusakan komponen terbakar tidak mudah. Setelah dilakukan pembelian puluhan PCB dan donasi PCB dari beberapa relasi hanya diperoleh satu buah PCB dengan komponen terbakar. Kesulitan mendapatkan PCB dengan kerusakan ini yang menyebabkan data set $P C B$-defect dan DeepPCB menggunakan kerusakan sintetis. Sayangnya menambahkan kesan terbakar terhadap komponen tidak semudah memutus jalur tembaga di PCB. Karena itu pengumpulan data dilakukan melalui data sekunder. Data ini diperoleh dari video reparasi PCB yang tersedia di beberapa kanal Youtube. Misalnya kanal Northridgefix [13] dan LivyuFPV[14] sering menampilkan proses reparasi PCB dengan komponen yang terbakar seperti contoh Gambar 5. 


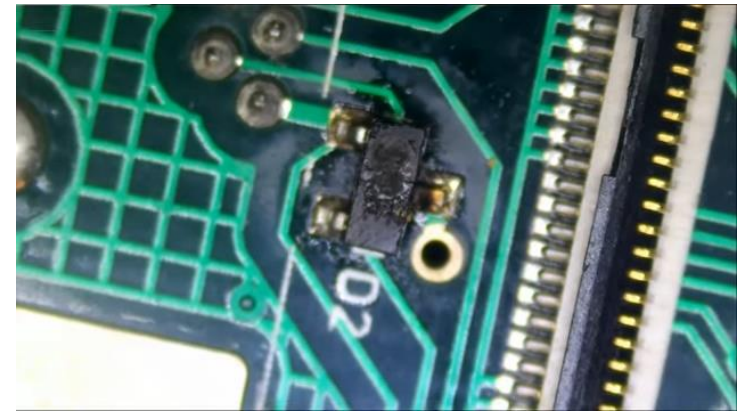

Gambar 5. Citra PCB dengan Komponen Terbakar dari Video Kanal Youtube Northridgefix

Dari kanal Youtube di atas dapat dikumpulkan 100 buah citra PCB yang unik. Jumlah ini bisa ditambahkan lagi dengan mengambil citra ketika PCB digerakkan oleh pemilik kanal. Selain itu dapat dilakukan augmentasi dengan transformasi flip atau geometri lainnya untuk mendapatkan jumlah citra yang lebih banyak.

\subsection{Anotasi Data}

Agar dapat dijadikan bahan belajar model kecerdasan buatan maka citra-citra tersebut memerlukan pra-pemrosesan. Setidaknya ada dua pra-pemrosesan yang perlu dilakukan. Pra-pemrosesan yang pertama adalah anotasi data. Salah satu bentuk anotasi adalah memberikan informasi koordinat, panjang, dan lebar dari bounding box komponen terbakar. Dalam satu citra dimungkinkan ada lebih dari satu komponen terbakar. Aplikasi anotasi LabelImg digunakan untuk menambahkan informasi bounding box kepada kumpulan citra yang diperoleh. Hasil anotasi adalah pasangan satu berkas citra dengan berkas $x \mathrm{ml}$. Isi berkas xml antara lain adalah nama file citra yang dianotasi, direktori files, dimensi asal citra, nama obyek komponen terbakar, koordinat kiri atas dan kanan bawah dari bounding box komponen terbakar. Jadi dalam satu berkas xml ini ada satu atau lebih obyek komponen terbakar dengan koordinat bounding box-nya. Karena hanya ada satu kelas komponen terbakar maka nama kelas hanya satu. Berkas-berkas $x m l$ ini selanjutnya dijadikan satu berkas Comma Separated Value (csv) dengan format pada tabel 2:

Tabel 2. Variabel CSV XML Anotasi

\begin{tabular}{cll}
\hline No & Kolom & \multicolumn{1}{c}{ Variabel } \\
\hline 1 & Satu & nama file \\
2 & Dua & Lebar \\
3 & Tiga & Tinggi \\
4 & Empat & Kelas Objek \\
5 & Lima & Koordinat sumbu x1 \\
6 & Enam & Koordinat sumbu y1 \\
7 & Tujuh & Koordinat sumbu x2 \\
8 & Delapan & Koordinat sumbu y2 \\
\hline
\end{tabular}

\section{HASIL DAN PEMBAHASAN}

Selanjutnya berkas $c s v$ ini harus dikonversi ke dalam format yang bisa dibaca oleh pustaka kecerdasan buatan yang akan dipakai. Proses pelatihan dan implementasi kecerdasan buatan bisa dilakukan di komputer lokal maupun memakai infrastruktur yang disediakan perusahaan seperti Amazon, Microsoft, IBM, dan Google. Setiap infrastruktur mendukung beberapa framework yang sama seperti TensorFlow. Sementara framework lain seperti Pytorch dan Keras tidak selalu didukung oleh semua perusahaan. Karena framework yang paling umum tersedia adalah TensorFlow maka berkas $c s v$ hasil proses sebelumnya harus dikonversi ke format yang bisa dibaca oleh framework tersebut. Sebenarnya TensorFlow mampu membaca berkas csv tetapi proses pelatihan nanti akan menjadi lebih lama. Karena itu csv akan dikonversi ke format TFRecord.

Proses konversi $\operatorname{csv}$ ke TFRecord bisa dilakukan dengan notebook di jupyter atau memakai layanan dari pihak ketiga seperti roboflow. Cara apapun yang dipakai akan diperlukan berkas csv dan berkas citra-citra yang ditulis dalam csv. Semua berkas ini akan disatukan dalam sebuah berkas biner format TFRecord. Infrastruktur yang digunakan dalam penelitian ini adalah Google Colab. Berkas TFRecord yang dibuat diunggah ke dalam drive dan kemudian nanti dipanggil melalui notebook dalam Google Colab. Selanjutnya data tersebut bisa digunakan untuk melatih dan menguji model kecerdasan buatan yang dikembangkan. Ringkasan proses pengumpulan data citra PCB dengan komponen terbakar diperlihatkan pada Gambar 6. 

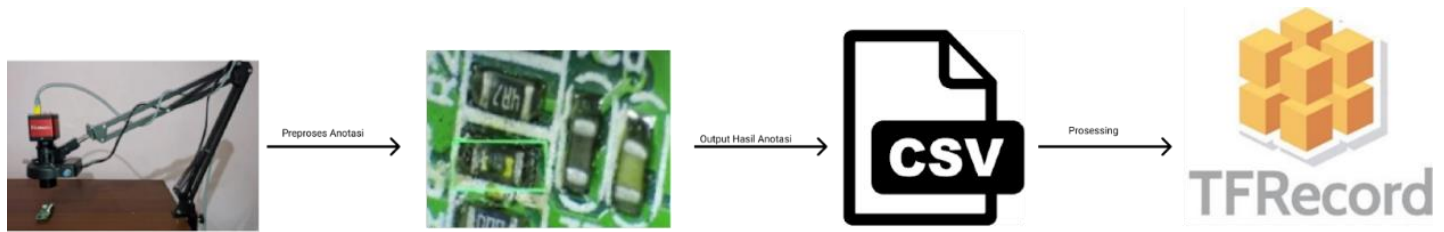

Gambar 6. Ringkasan Proses Pengumpulan Citra PCB

Prosedur penggunaan data TFRecord adalah dengan mengikat (mount) folder yang mengandung data tersebut dari Google Colab. Ketika menjalankan prosedur pengikatan drive dengan Google Colab akan diperoleh tautan ke akun Google dan autorisasi terhadap akses Google Colab. Kode autorisasi akan digunakan pada tautan yang diberikan. Setelah autorisasi selesai maka data TFRecord bisa diakses dari kode Google Colab. Penggunaan data biasanya dibagi menjadi data pelatihan dan pengujian. Banyaknya data pelatihan biasanya $80-90 \%$ dari data keseluruhan. Sedangkan untuk pengujian $10-20 \%$ data keseluruhan. Pembagian ini seharusnya dilakukan sebelum citra dibuatkan berkas $c s v$ dan TFRecord-nya. Jadi nanti yang dipanggil dalam Google Colab saat membentuk model adalah data pelatihan saja. Sedangkan data pengujian digunakan untuk memverifikasi model yang dibentuk dengan data yang benar-benar belum pernah dilihat dan diawasi performanya.

Kumpulan data PCB dengan komponen terbakar ini telah digunakan dalam penelitian yang dilakukan oleh [15]. Pelatihan dan pengujian dengan Model EfficientDet memberikan hasil yang cukup baik yaitu Mean Average Precission $(m A P)$ sebesar $90 \%$. Karena belum ada penelitian sejenis yang menggunakan PCB dengan komponen terbakar maka masih terbuka peluang untuk memperbaiki kinerja hasil identifikasi dengan kecerdasan buatan. Model hasil pelatihan dan pengujian bisa digunakan untuk mengidentifikasi komponen terbakar di PCB. Sayangnya hanya ada satu PCB dengan komponen terbakar yang bisa diuji coba. Dalam uji coba model dari EfficientDet mampu mengenali komponen terbakar dengan baik seperti diperlihatkan pada Gambar 7. Komponen terbakar ini belum pernah diketahui sama sekali oleh sistem sehingga bounding box yang dihasilkan dikatakan berhasil menemukan komponen yang terbakar.

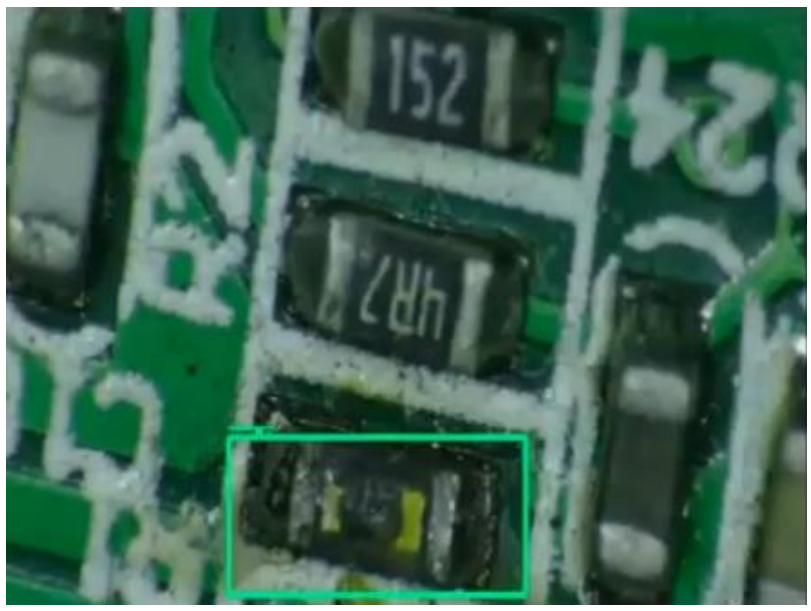

Gambar 7. Hasil Identifikasi Waktu Nyata Komponen Terbakar Berbasis Model Hasil EfficientDet

\section{KESIMPULAN}

Pada penelitian ini telah berhasil dikumpulkan data citra PCB dengan komponen terbakar. Mendapatkan PCB yang sesungguhnya dengan komponen terbakar sangat sulit. Dari puluhan PCB yang diperoleh, hanya satu saja yang memiliki komponen terbakar. Karena itu pencarian data dilakukan dari video perbaikan PCB di beberapa kanal Youtube. Dari kanal tersebut bisa diidentifikasi beberapa komponen yang sering mendapatkan kerusakan akibat terbakar. Biasanya komponen ini berada di bagian daya dari PCB di mana sumber daya dengan tegangan berbeda level diregulasi dan didistribusikan. Komponen yang sering terbakar antara lain resistor, kapasitor, dan mosfet. Kumpulan data telah digunakan dalam penelitian tugas akhir mahasiswa dengan menggunakan EfficientDet sebagai kecerdasan buatan. Hasilnya dalam pelatihan dan pengujian memberikan performa yang cukup baik. Model hasil pelatihan pun bisa digunakan untuk mendeteksi komponen terbakar secara waktu nyata. Data citra dengan anotasi atau hasil konversinya ke csv atau TFRecord tidak bisa dipublikasikan karena belum mendapatkan izin dari pemilik kanal Youtube bersangkutan. Peneliti lain yang berminat dapat mengakses video yang ada dalam list yang telah kami buat. Dengan menjalankan proses seperti dalam makalah ini diharapkan peneliti dapat membangun kumpulan data yang berbeda dari sumber yang sama. Aktivitas seperti ini sama seperti augmentasi data yaitu menambahkan data dari sumber yang sama dengan perlakuan yang berbeda. Penelitian selanjutnya dapat mengeksplorasi model kecerdasan buatan lain seperti MobileNet, U-Net, U-Net, dan Yolo dengan berbagai versinya[16]. Komparasi antara model dengan 
variasi kumpulan data komponen terbakar masih sangat terbuka Selain itu penelitian juga bisa diarahkan untuk deteksi komponen terbakar secara waktu nyata yang disiarkan secara langsung. Aplikasi dari deteksi seperti itu misalnya digunakan untuk pendeteksian komponen terbakar jarak jauh. Dengan kondisi pandemi seperti sekarang, aplikasi tersebut memiliki celah penggunaan yang aplikatif misalnya dengan bantuan streamlit[17].

\section{REFERENCES}

[1] B. Xia, J. Cao, and C. Wang, "SSIM-NET: Real-Time PCB Defect Detection Based on SSIM and MobileNet-V3," in 2019 2nd World Conference on Mechanical Engineering and Intelligent Manufacturing (WCMEIM), Nov. 2019, pp. 756-759. doi: 10.1109/WCMEIM48965.2019.00159.

[2] Y.-S. Deng, A.-C. Luo, and M.-J. Dai, "Building an Automatic Defect Verification System Using Deep Neural Network for PCB Defect Classification," in 2018 4th International Conference on Frontiers of Signal Processing (ICFSP), Sep. 2018, pp. 145-149. doi: 10.1109/ICFSP.2018.8552045.

[3] S. Khalilian, Y. Hallaj, A. Balouchestani, H. Karshenas, and A. Mohammadi, "PCB Defect Detection Using Denoising Convolutional Autoencoders," in 2020 International Conference on Machine Vision and Image Processing (MVIP), Feb. 2020, pp. 1-5. doi: 10.1109/MVIP49855.2020.9187485.

[4] S. Tang, F. He, X. Huang, and J. Yang, “Online PCB Defect Detector On A New PCB Defect Dataset,” Feb. 2019.

[5] W. Huang, P. Wei, M. Zhang, and H. Liu, "HRIPCB: a challenging dataset for PCB defects detection and classification," The Journal of Engineering, vol. 2020, no. 13, pp. 303-309, Jul. 2020, doi: 10.1049/joe.2019.1183.

[6] W. Huang and P. Wei, "A PCB Dataset for Defects Detection and Classification," Jan. 2019.

[7] J. Redmon and A. Farhadi, "YOLOv3: An Incremental Improvement," 2018. [Online]. Available: https://pjreddie.com/yolo/.

[8] S. Ren, K. He, R. Girshick, and J. Sun, "Faster R-CNN: Towards Real-Time Object Detection with Region Proposal Networks," IEEE Transactions on Pattern Analysis and Machine Intelligence, vol. 39, no. 6, pp. 1137-1149, Jun. 2017, doi: 10.1109/TPAMI.2016.2577031.

[9] R. Ding, L. Dai, G. Li, and H. Liu, "TDD-net: a tiny defect detection network for printed circuit boards," CAAI Transactions on Intelligence Technology, vol. 4, no. 2, pp. 110-116, Jun. 2019, doi: 10.1049/TRIT.2019.0019.

[10] C. Pramerdorfer and M. Kampel, "A dataset for computer-vision-based PCB analysis," in 2015 14th IAPR International Conference on Machine Vision Applications (MVA), May 2015, pp. 378-381. doi: 10.1109/MVA.2015.7153209.

[11] G. Mahalingam, K. M. Gay, and K. Ricanek, "PCB-METAL: A PCB Image Dataset for Advanced Computer Vision Machine Learning Component Analysis," in 2019 16th International Conference on Machine Vision Applications (MVA), May 2019, pp. 1-5. doi: 10.23919/MVA.2019.8757928.

[12] L. Hangwei, M. Dhwani, P. Olivia, A. Navid, T. Mark, and Damon L. Woodard, "FICS-PCB: A Multi-Modal Image Dataset for Automated Printed Circuit Board Visual Inspection," 2020, Accessed: Dec. 31, 2021. [Online]. Available: https://eprint.iacr.org/2020/366

[13] NorthridgeFix, "NorthridgeFix - YouTube," 2021. https://www.youtube.com/c/NorthridgeFix (accessed Dec. 31, 2021).

[14] Livyu FPV, "Livyu FPV - YouTube," 2021. https://www.youtube.com/channel/UCpTR69y-aY-JL4_FPAAPUlw (accessed Dec. 31, 2021)

[15] G. Melinia, I. Kadhafi, dan R. W. Sitepu, "Sistem Pendeteksi Objek Kerusakan Burnout pada Modul PCB dengan Memanfaatkan Arsitektur Efficientdet," Tugas Akhir, Politeknik Negeri Bandung, 2021.

[16] X. Zou, "A Review of object detection techniques," Proceedings - 2019 International Conference on Smart Grid and Electrical Automation, ICSGEA 2019, pp. 251-254, Aug. 2019, doi: 10.1109/ICSGEA.2019.00065.

[17] Streamlit Inc., "Streamlit • The fastest way to build and share data apps," 2021. https://streamlit.io/ (accessed Dec. 31, 2021). 